\title{
Among Patients With Facial Fractures, Geriatric Patients Have an Increased Risk for Associated Injuries
}

\section{Toivari, Miika}

2016-07

Toivari , M , Suominen , A L , Lindqvist , C \& Thoren , H 2016 , ' Among Patients With Facial Fractures, Geriatric Patients Have an Increased Risk for Associated Injuries ' , Journal of Oral and Maxillofacial Surgery , vol. 74 , no. 7 , pp. 1403-1409 . https://doi.org/10.1016/j.joms.2016.02.001

http://hdl.handle.net/10138/224072

https://doi.org/10.1016/j.joms.2016.02.001

publishedVersion

Downloaded from Helda, University of Helsinki institutional repository.

This is an electronic reprint of the original article.

This reprint may differ from the original in pagination and typographic detail.

Please cite the original version. 


\title{
Among Patients With Facial Fractures, Geriatric Patients Have an Increased Risk for Associated Injuries
}

\author{
Miika Toivari, DDS, * Anna Liisa Suominen, DDS, PbD, MSc, $\dagger$ \\ Christian Lindqvist, MD, DDS, PhD, $\ddagger$ and Hanna Thorén, $M D, D D S, P b D \oint$
}

Purpose: It is hypothesized that facial trauma-associated injuries (AIs) are more frequent and severe in elderly than in younger adult patients. The purpose of this study was to determine the occurrence of, reasons for, and severity of $\mathrm{AI}$ in geriatric facial fractures and to compare the differences between geriatric and younger adult patients.

Materials and Methods: Two patient cohorts were included in this cross-sectional retrospective study. Geriatric patients were at least 65 years old $(n=117)$ and younger controls were 20 to 50 years old $(n=$ 136). The main predictor was age, the primary outcome was AI, and secondary outcomes were affected organ system, multiple AIs, polytrauma, and mortality during hospitalization. The other explanatory variables were gender, trauma mechanism, and type of facial fracture. Statistical methods included $\chi^{2}$ tests, risk analyses with $2 \times 2$ table, and logistic regression analyses.

Results: AIs were significantly more common in geriatric patients (44.0\%) than in younger controls (25.0\%; $P<.001)$. Also, multiple AIs $(P=.003)$, polytrauma $(P=.039)$, mortality $(P=.008)$, limb injuries $(P=.005)$, and spine injuries $(P=.041)$ were significantly more common in the elderly. In the risk analyses, geriatric patients had a 1.8-fold risk for AI, a 2.6-fold risk for multiple AIs, and a 2.2-fold risk for polytrauma.

Conclusions: AIs are much more frequent and severe in geriatric patients, and the elderly die more often of their injuries. The results emphasize that elderly patients require specific attention and multiprofessional collaboration in the diagnosis and sequencing of trauma treatment.

(C) 2016 American Association of Oral and Maxillofacial Surgeons

J Oral Maxillofac Surg 74:1403-1409, 2016

Associated injuries (AIs) in patients with facial fractures are frequent. In studies that have excluded brain concussion, wounds, and other minor soft tissue injuries, the AI rate in patients with facial fracture has ranged from 18.2 to $25.2 \%{ }^{1,2}$ When skin excoriations have been included, the rate has been as high as $35 \%{ }^{3}$ Particularly high rates of AI have been observed in association with panfacial fractures $(53 \%)^{4}$ and high-speed injury mechanisms, such as

*Resident, Department of Oral and Maxillofacial Diseases, University of Helsinki and Helsinki University Hospital, Helsinki, Finland.

$\dagger$ Professor, Departments of Health, Functional Capacity and Welfare and Environmental Health, National Institute for Health and Welfare, Helsinki/Kuopio, Finland; Department of Oral Public Health, Institute of Dentistry, University of Eastern Finland, Kuopio, Finland; Department of Oral and Maxillofacial Surgery, Kuopio University Hospital, Kuopio, Finland.

$\ddagger$ Professor, Department of Oral and Maxillofacial Diseases, University of Helsinki and Helsinki University Hospital, Helsinki, Finland. motor vehicle accidents (MVAs; 69.2 to $99.3 \%)^{1,5}$ and falls from a height $(76.9 \%) .{ }^{1}$ AIs also have been related to age; the AI rate in patients at least 60 years old has been observed to be $48.7 \%$, with the corresponding figure for patients younger than 60 years being only $22.7 \%$. ${ }^{1}$ However, the authors are not aware of studies to date that have examined in detail $\mathrm{AI}$ in geriatric patients with fractures of the facial bones.

$\S$ Docent, Department of Oral and Maxillofacial Diseases, University of Helsinki and Helsinki University Hospital, Helsinki, Finland.

Address correspondence and reprint requests to Dr Toivari: Reppukatu 2 C42, 00770 Helsinki, Finland; e-mail: miika.toivari@ helsinki.fi

Received September 182015

Accepted February 12016

(c) 2016 American Association of Oral and Maxillofacial Surgeons

0278-2391/16/00147-6

hitp://dx.doi.org/10.1016/i.joms.2016.02.001 
In a recently published study, Keller et $\mathrm{al}^{6}$ presented admission data on patients with orthopedic injuries comparing the severity of injuries in 597 patients at least 65 years old with 6,573 patients no older than 65 years. The data showed that the mean Injury Severity Score, Trauma Injury Severity Score, and Abbreviated Injury Score for the brain, thorax, abdomen, and spine were considerably worse in the elderly. Moreover, the death rate of elderly patients was 3 times that of the younger population. Based on these results, it can be hypothesized that elderly patients with facial fractures are more severely injured and die more frequently than younger patients.

The purpose of the present study was to investigate AI in geriatric patients with fractures of the facial bones. The specific aims were to design and implement a cohort study to clarify the occurrence of, reasons for, and severity of AI in geriatric patients and to compare the occurrence and types of AI between geriatric patients and younger controls. The hypotheses were that AIs are frequent in geriatric patients and that they occur more frequently and are more severe in geriatric patients than in younger controls.

\section{Materials and Methods}

\section{STUDY DESIGN}

To address the research aim, a retrospective cohort study was designed and implemented. Included were patients at least 65 years old who had been diagnosed with facial fractures at a level 1 trauma center during the 2-year period from January 1, 2006 through December 31, $2007(n=117)$. From previously published data, ${ }^{1}$ the authors identified patients 20 to 50 years old who had been diagnosed with facial fractures and included them as younger controls $(n=136)$.

\section{STUDY VARIABLES}

The primary outcome variable for the geriatric patients and younger controls was AI (ie, yes or no). The secondary outcome variables were affected organ system, multiple AIs, polytrauma, and mortality during hospitalization. AIs were defined as any major injury outside the face, excluding brain concussions, wounds, and other minor soft tissue injuries. Their precise anatomic sites were recorded, and they were further classified according to the affected organ system and severity. The affected organ systems were classified as 1) brain, 2) chest, 3) abdomen, 4) spine, and 5) limbs. Multiple AIs were established for patients who had at least 2 different AIs. Polytrauma was defined as the involvement of at least 2 organ systems and at least 1 life-threatening injury.

The primary predictor variable was age (ie, geriatric patients vs younger controls). Other explanatory vari- ables included in the analyses were gender, trauma mechanism, and type of facial fracture. The trauma mechanism was classified as a ground-level fall, fall from a height, assault, bicycle accident, MVA, sportsrelated accident, being hit by a blunt object, and gunshot accident. For each patient, 1 of the following 9 groups of facial fracture was assigned: 1) isolated mandibular fracture ( $\geq 1$ fracture); 2) isolated zygomatico-orbital fracture (ie, tripod zygomatic fracture or isolated zygomatic arch fracture); 3) isolated orbital fracture (ie, isolated orbital floor, medial wall, or roof fracture); 4) isolated nasal fracture; 5) extensive midfacial fracture (ie, Le Fort I to III, naso-orbitoethmoidal, or multiple midfacial fractures); 6 ) isolated upper third fracture (ie, fractures of the frontal sinus or anterior skull base); 7) combined fractures (ie, mandibular + midfacial fracture, midfacial + upper third fracture, or panfacial fracture extending to all facial thirds); 8) isolated fractures of the wall of the maxillary sinus; and 9) isolated dentoalveolar injury.

\section{DATA ANALYSIS}

The $\chi^{2}$ tests were performed to examine the statistical significance of differences between the outcomes and the primary predictor (age group) and other explanatory variables and between the primary predictor and other variables. Risk ratios (RRs) with 95\% confidence intervals ( $95 \%$ CIs) were calculated to examine the risk of all outcomes by age group. Logistic regression analyses were conducted to study the association between age group and the primary outcome (associated injury) and expressed as odds ratios (ORs) and 95\% CIs. Bivariate associations were further adjusted for gender, trauma mechanism, and type of facial fracture.

\section{ETHICAL CONSIDERATIONS}

The internal review board of the Division of Musculoskeletal Surgery, Helsinki University Hospital (Helsinki, Finland) approved the study.

\section{Results}

Table 1 presents the association between gender, trauma mechanism, type of facial fracture and the primary predictor variable (age). The frequency of male patients was significantly higher among younger controls than among geriatric patients $(P<.001)$. Ground-level fall $(P<.001)$ and unknown trauma mechanism $(P=.008)$ were significantly more frequent in geriatric patients than in younger controls, whereas assault $(P<.001)$, bicycle accidents $(P=$ $.021)$, and sports-related injuries $(P=.005)$ were more frequent in younger controls. Isolated orbital fractures $(P=.015)$ and isolated fractures of the maxillary sinus wall $(P=.034)$ were significantly more 
Table 1. ASSOCIATION BETWEEN GENDER, TRAUMA MECHANISM, TYPE OF FACIAL FRACTURE, AND PRIMARY PREDICTOR

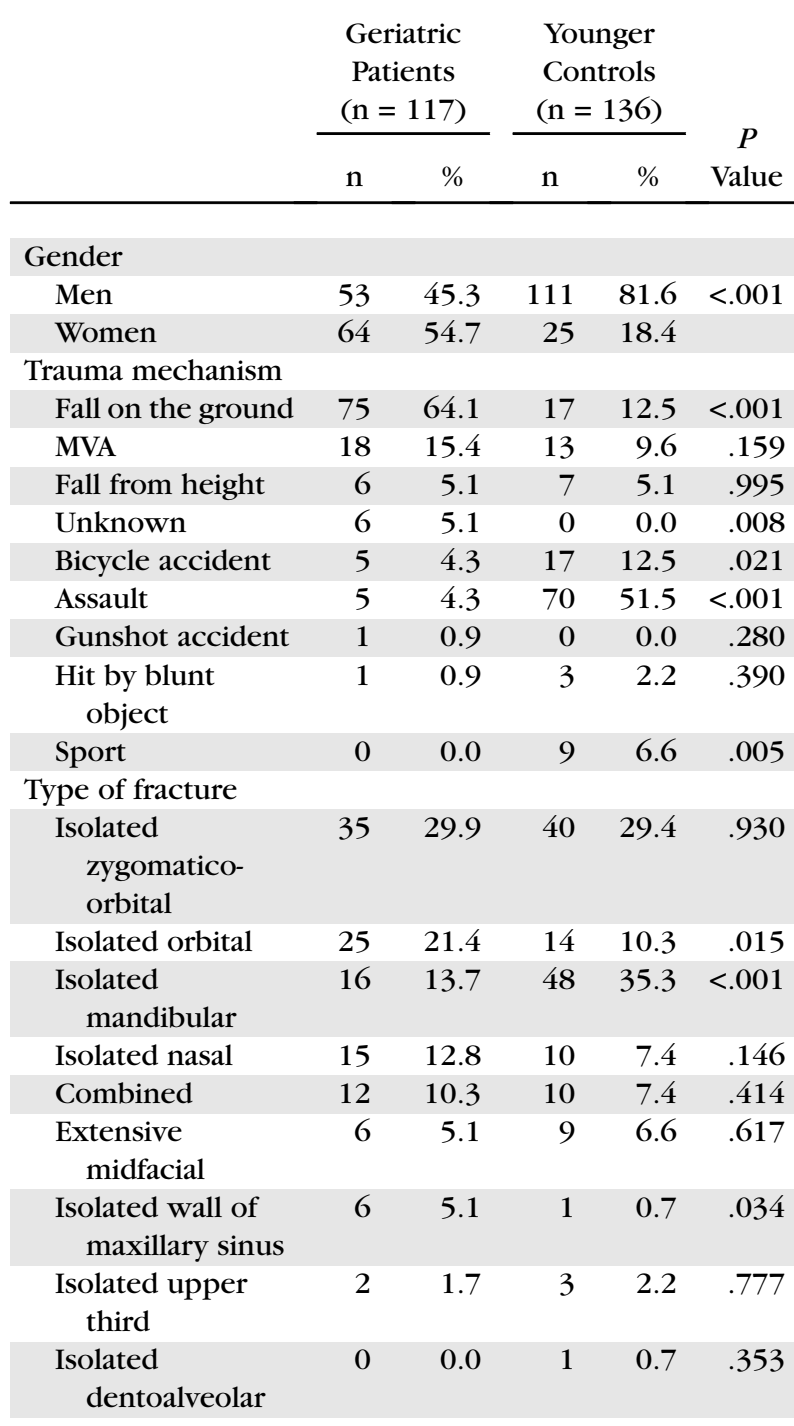

Abbreviation: MVA, motor vehicle accident

Toivari et al. Associated Injuries in Geriatric Patients. J Oral Maxillofac Surg 2016.

common in geriatric patients, whereas isolated mandibular fractures were more frequent in younger controls $(P<.001)$.

Table 2 presents the relation between gender, trauma mechanism, type of facial fracture and the primary outcome (AI). The most significant predictors for AI were MVA $(P<.001)$, fall from a height $(P<.001)$, and isolated fracture of the maxillary sinus wall $(P<$ .001). Other statistically significant predictors were unknown trauma mechanism $(P=.010)$ and combined facial fracture $(P=.033)$.

Table 3 presents the association between AI, affected organ system, multiple AIs, polytrauma, mortality and age groups. AIs in general $(P<.001)$ and $\operatorname{limb}(P=$ $.005)$ and spine $(P=.041)$ injuries in particular were more frequent in geriatric patients than in controls. Also, multiple AIs $(P=.003)$, polytrauma $(P=.039)$, and mortality $(P=.008)$ were more frequent in geriatric patients. Of the 6 geriatric patients who died during hospitalization, 2 had multiple AIs and 4 had polytrauma. The types of facial fracture in these 6 patients were combined ( 2 of 6 ), extensive midfacial ( 1 of 6 ), isolated zygomatico-orbital ( 1 of 6 ), isolated orbital ( 1 of 6 ), and isolated fracture of the maxillary sinus wall ( 1 of 6 ).

Table 4 lists the RRs with 95\% CIs of all outcomes by age group. Geriatric patients had a significantly higher risk for AI in general $(P=.002)$ and multiple AIs $(P=$ $.004)$, polytrauma $(P=.050)$, and limb injuries $(P=$ $.006)$ in particular. Moreover, geriatric patients had a 1.8-fold risk for AI, a 2.6-fold risk for multiple AIs, and a 2.2-fold risk for polytrauma. Geriatric patients also had a 3.5-fold risk for spine injuries, but the difference was not relevant.

Logistic regression analyses were conducted to study the association between age group and the primary outcome (associated injury) and expressed as ORs and 95\% CIs. Bivariate associations were further adjusted for gender, trauma mechanism, and type of facial fracture.

Table 5 presents the results of logistic regression analyses. In bivariate analyses, geriatric patients had a 2.4-fold risk for AI compared with younger controls $(P<.001)$. When adjusted for gender, trauma mechanism, and fracture type, the risk for AI was 2.1-fold, but the association was not statistically relevant.

Table 6 presents sites of injuries in more detail. Geriatric patients altogether sustained 1.7 times the number of AIs compared with younger controls. For the geriatric patients, the most common injuries were upper limb fracture (21.4\%), brain contusion (11.1\%), and lower limb fracture (9.4\%). In younger adult patients, the most common injuries were brain contusion (7.4\%) and upper limb fracture (5.9\%). Although spine injuries were few in the 2 groups, the rate of cervical spine injuries was clearly higher in the elderly (6.8\%) than in the controls (1.5\%).

\section{Discussion}

The purpose of the present study was to investigate AIs in geriatric patients with fractures of the facial bones. The specific aims were to design and implement a cohort study to clarify the occurrence of, reasons for, and severity of AIs in geriatric patients and to compare the occurrence and types of AI between geriatric patients and younger controls. The hypotheses were that AIs are frequent in geriatric patients and that they occur more frequently and are more severe in geriatric patients than in younger controls. 
Table 2. ASSOCIATION BETWEEN GENDER, TRAUMA MECHANISM, TYPE OF FACIAL FRACTURE AND PRIMARY OUTCOME

\begin{tabular}{|c|c|c|c|c|c|}
\hline & \multicolumn{2}{|c|}{ AI Present } & \multicolumn{2}{|c|}{ AI Absent } & \multirow[b]{2}{*}{$P$ Value } \\
\hline & Patients, $\mathrm{n}$ & $\%$ & Patients, $\mathrm{n}$ & $\%$ & \\
\hline Population & 86 & 34.0 & 167 & 66.0 & \\
\hline \multicolumn{6}{|l|}{ Gender } \\
\hline Men & 58 & 35.4 & 106 & 64.6 & .531 \\
\hline Women & 28 & 31.5 & 61 & 68.5 & \\
\hline \multicolumn{6}{|l|}{ Trauma mechanism } \\
\hline Fall on the ground & 24 & 26.1 & 68 & 73.9 & .045 \\
\hline MVA & 27 & 87.1 & 4 & 12.9 & $<.001$ \\
\hline Fall from height & 10 & 76.9 & 3 & 23.1 & $<.001$ \\
\hline Unknown & 5 & 83.3 & 1 & 16.7 & .010 \\
\hline Bicycle accident & 7 & 31.8 & 15 & 68.2 & .822 \\
\hline Assault & 10 & 13.3 & 65 & 86.7 & $<.001$ \\
\hline Gunshot accident & 0 & 0.0 & 1 & 100.0 & .472 \\
\hline Hit by blunt object & 2 & 50.0 & 2 & 50.0 & .450 \\
\hline Sport & 1 & 11.1 & 8 & 88.9 & .140 \\
\hline \multicolumn{6}{|l|}{ Type of fracture } \\
\hline Isolated zygomatico-orbital & 28 & 37.3 & 47 & 62.7 & .466 \\
\hline Isolated orbital & 13 & 33.3 & 26 & 66.7 & .925 \\
\hline Isolated mandibular & 8 & 1.3 & 56 & 87.5 & $<.001$ \\
\hline Isolated nasal & 9 & 36.0 & 16 & 64.0 & .823 \\
\hline Combined & 12 & 54.5 & 9 & 40.9 & .033 \\
\hline Extensive midfacial & 6 & 40.0 & 10 & 66.7 & .613 \\
\hline Isolated wall of maxillary sinus & 7 & 100.0 & 0 & 0.0 & $<.001$ \\
\hline Isolated upper third & 3 & 60.0 & 2 & 40.0 & .215 \\
\hline Isolated dentoalveolar & 0 & 0.0 & 1 & 100.0 & .472 \\
\hline
\end{tabular}

Abbreviations: AI, associated injury; MVA, motor vehicle accident.

Toivari et al. Associated Injuries in Geriatric Patients. J Oral Maxillofac Surg 2016.

The hypotheses were confirmed. AI $(P<.001)$, multiple AIs $(P=.003)$, polytrauma $(P=.039)$, and mortality $(P=.008)$ were significantly more frequent in geriatric patients than in younger controls. In the risk analyses, geriatric patients had a 1.8-fold risk for AI, a 2.6-fold risk for multiple AIs, and a 2.2-fold risk for polytrauma. The most common AIs in the elderly were upper limb fractures and brain contusions. Limb injuries $(P=$ $.005)$ and spine injuries $(P=.041)$ were significantly more common in the elderly than in younger controls.

According to the results of several previously published studies, geriatric patients with general trauma are more severely injured, remain longer in the hospital and intensive care units, and die of their injuries more frequently than younger controls. ${ }^{6-8}$ For facial fractures, the results of the present study clearly show that geriatric patients also are more severely injured than younger ones. The mortality rate of geriatric patients in the present study (5.1\%) is at the lower end of what has previously been reported ( 4.4 to $18.2 \%)^{6-8}$; however, the rate is notable and significantly higher than in younger controls $(0 \% ; P=.008)$.
Several factors predispose elderly patients to death after trauma. In addition to various age-related changes, geriatric patients have comorbidities and medications that not only compromise recovery but also increase the severity of sustained injuries. An additional important factor that increases morbidity and mortality in elderly patients with trauma is under-triage, which has been reported by Rogers et $\mathrm{l}^{9}$ to occur in $15 \%$ of geriatric patients with trauma. Moreover, under-triaged patients were almost twice as likely to die of their injuries compared with correctly triaged patients. Subsequently, the quality of care and functional outcome of elderly trauma patients were found to improve when geriatric consultation was implemented. ${ }^{10,11}$ The establishment of a geriatric trauma service for patients at least 60 years old resulted in a decrease in the average emergency department (ED) length of stay, average ED to operating room time, average surgical intensive care unit length of stay, and average hospital length of stay. ${ }^{12}$ Moreover, the rates of mortality, pneumonia, respiratory failure, and urinary tract infections decreased. 


\section{Table 3. ASSOCIATION BETWEEN AI, AFFECTED ORGAN SYSTEM, MULTIPLE AIS, POLYTRAUMA, MORTALITY AND AGE GROUPS}

\begin{tabular}{cccc}
$\begin{array}{c}\text { Geriatric } \\
\text { Patients } \\
(\mathrm{n}=117)\end{array}$ & & $\begin{array}{c}\text { Younger } \\
\text { Controls } \\
(\mathrm{n}=136)\end{array}$ & \\
\cline { 1 - 2 } $\mathrm{n} \quad \%$ & & $\mathrm{n} \quad \%$ & $P$ Value $^{*}$
\end{tabular}

\begin{tabular}{|rrrrrr}
\hline $\begin{array}{l}\text { AIs present } \\
\quad \text { Yes }\end{array}$ & 52 & 44.4 & 34 & 25.0 & $<.001$ \\
\hline $\begin{array}{l}\text { Affected organ system } \\
\text { Limb }\end{array}$ & 32 & 27.4 & 18 & 13.2 & .005 \\
\hline Brain & 22 & 18.8 & 17 & 12.5 & .166 \\
\hline Chest & 13 & 11.1 & 8 & 5.9 & .133 \\
\hline Spine & 9 & 7.7 & 3 & 2.2 & .041 \\
\hline Abdomen & 0 & 0.0 & 1 & 0.7 & .353 \\
\hline Severity of AI & & & & & \\
\hline Multiple AIs & 25 & 21.4 & 11 & 8.1 & .003 \\
\hline Polytrauma & 17 & 14.5 & 9 & 6.6 & .039 \\
\hline Mortality & 6 & 5.1 & 0 & 0.0 & .008 \\
\hline
\end{tabular}

Abbreviation: AI, associated injury.

${ }^{*}$ By $\chi^{2}$ test.

Toivari et al. Associated Injuries in Geriatric Patients. J Oral Maxillofac Surg 2016.

Studies specifically focusing on the association between facial fractures and AI in geriatric patients are scarce. ${ }^{13,14}$ Kloss et al ${ }^{13}$ compared the causes and types of facial injuries and concomitant injuries in patients older than 65 years $(n=774)$ with those in younger patients $(n=11,798)$. The overall rate of concomitant injuries in the elderly patients was not presented. However, based on rates reported by the investigators for each separate injury, and assuming that each elderly patient had only 1 concomitant injury, the overall AI rate in geriatric patients was approximately $40 \%$. This figure is close to that found in the present study (44.4\%).

When the occurrence of injuries to specific organ systems in geriatric patients is compared, notable dis-

\section{Table 5. LOGISTIC REGRESSION ANALYSIS FOR AI AND AGE}

\begin{tabular}{lcc} 
& OR $(95 \% \mathrm{CI})$ & $P$ Value \\
\hline Unadjusted & & \\
$\quad$ Geriatric group & $2.4(1.4-4.1)$ & $<.001$ \\
Younger control & 1.0 & 1.0 \\
Adjusted* & & .119 \\
\hline Geriatric group & $2.1(0.8-5.2)$ & 1.0 \\
\hline Younger control & 1.0 &
\end{tabular}

Abbreviations: CI, confidence interval; OR, odds ratio.

* Adjusted for gender, trauma mechanism, and type of facial fracture.

Toivari et al. Associated Injuries in Geriatric Patients. J Oral Maxillofac Surg 2016.

crepancies can be observed between the results of Kloss et $\mathrm{al}^{13}$ and those of the present study. Brain injuries were far more infrequent in the present study (18.8 vs approximately $35 \%)$. Conversely, limb (27.4 vs $3.9 \%$ ), chest (11.1 vs $1.9 \%$ ), and spine ( 7.7 vs $1.7 \%$ ) injuries were far more frequent in the present study. The authors propose 2 reasons for the discrepancies in the results. First, Kloss et $\mathrm{al}^{13}$ included concussions, contusions, subdural hematomas, and epidural hematomas as concomitant injuries. In the present study, concussions were not included, explaining the lower frequency of brain injuries. Second, in addition to patients with facial fracture, Kloss et $\mathrm{al}^{13}$ included patients with soft tissue injuries and dental injuries. More than half the geriatric facial injuries in their study were of a less severe nature than facial fractures (ie, $46 \%$ soft tissue injuries and $7 \%$ dental injuries), probably explaining the substantially lower rates of limb, chest, and spine injuries than in the present study.

As recorded in the present study and noted in previous publications, approximately 1 in every 10 adult patients with facial fractures has a brain injury. ${ }^{1-3,15}$ In the present study, a notably higher rate of brain injuries was observed in geriatric patients (18.8\%)

Table 4. RISK ANALYSIS BETWEEN PRIMARY PREDICTOR AND OUTCOME VARIABLES

\begin{tabular}{|c|c|c|c|c|c|c|c|c|c|}
\hline & $\begin{array}{c}\text { AI } \\
\text { Present }\end{array}$ & $\begin{array}{c}\text { Multiple } \\
\text { AIs }\end{array}$ & Polytrauma & Mortality & $\begin{array}{l}\text { Limb } \\
\text { Injury }\end{array}$ & $\begin{array}{l}\text { Brain } \\
\text { Injury }\end{array}$ & $\begin{array}{l}\text { Chest } \\
\text { Injury }\end{array}$ & $\begin{array}{l}\text { Spine } \\
\text { Injury }\end{array}$ & $\begin{array}{l}\text { Abdomen } \\
\text { Injury }\end{array}$ \\
\hline $\begin{array}{c}\text { Geriatric } \\
\text { group }\end{array}$ & $\begin{array}{c}1.8(1.2- \\
2.5)\end{array}$ & $\begin{array}{c}2.6(1.4- \\
5.1)\end{array}$ & $\begin{array}{c}2.2(1.0- \\
4.7)\end{array}$ & * & $\begin{array}{c}2.1(1.2- \\
3.5)\end{array}$ & $\begin{array}{c}1.5(0.8- \\
2.7)\end{array}$ & $\begin{array}{c}1.9(0.8- \\
4.4)\end{array}$ & $\begin{array}{r}3.5(1.0- \\
12.6)\end{array}$ & * \\
\hline $\begin{array}{l}\text { Younger } \\
\text { control }\end{array}$ & ref & ref & ref & & ref & ref & ref & ref & \\
\hline$P$ value & .002 & .004 & .050 & & .006 & .170 & .140 & .056 & \\
\hline
\end{tabular}

Note: Data are presented as risk ratio ( $95 \%$ confidence interval).

Abbreviations: AI, associated injury; ref, reference.

* Risk ratio not possible to define due to the absence of cases.

Toivari et al. Associated Injuries in Geriatric Patients. J Oral Maxillofac Surg 2016. 
Table 6. SITES OF AI IN GERIATRIC PATIENTS AND YOUNGER CONTROLS

\begin{tabular}{|c|c|c|c|c|}
\hline \multirow[b]{2}{*}{ Anatomic Site of AI } & \multicolumn{2}{|c|}{$\begin{array}{c}\text { Geriatric } \\
\text { Patients } \\
(\mathrm{n}=117)\end{array}$} & \multicolumn{2}{|c|}{$\begin{array}{c}\text { Younger } \\
\text { Controls } \\
(\mathrm{n}=136)\end{array}$} \\
\hline & $\mathrm{n}$ & $\%$ & $\mathrm{n}$ & $\%$ \\
\hline Upper limb fracture & 25 & 21.4 & 8 & 5.9 \\
\hline Brain contusion & 13 & 11.1 & 10 & 7.4 \\
\hline Lower limb fracture & 11 & 9.4 & 6 & 4.4 \\
\hline Rib fracture & 8 & 6.8 & 7 & 5.1 \\
\hline Cervical spine injury & 8 & 6.8 & 2 & 1.5 \\
\hline Subdural hematoma & 6 & 5.1 & 2 & 1.5 \\
\hline Intraparenchymal hematoma & 4 & 3.4 & 3 & 2.2 \\
\hline Subarachnoidal hematoma & 4 & 3.4 & 0 & - \\
\hline Pulmonary contusion & 4 & 3.4 & 2 & 1.5 \\
\hline Pneumothorax & 4 & 3.4 & 7 & 5.1 \\
\hline Pelvic fracture & 3 & 2.6 & 1 & 0.7 \\
\hline Hemothorax & 3 & 2.6 & 0 & - \\
\hline Sternum fracture & 2 & 1.7 & 0 & - \\
\hline Lumbal spine injury & 1 & 0.9 & 0 & - \\
\hline Cardiac contusion & 1 & 0.9 & 0 & - \\
\hline Epidural hematoma & 0 & - & 3 & 2.2 \\
\hline Thoracal spine injury & 0 & - & 1 & 0.7 \\
\hline Clavicle fracture & 0 & - & 4 & 2.9 \\
\hline Spleen rupture & 0 & - & 1 & 0.7 \\
\hline Liver rupture & 0 & - & 1 & 0.7 \\
\hline
\end{tabular}

Abbreviation: AI, associated injury.

Toivari et al. Associated Injuries in Geriatric Patients. J Oral Maxillofac Surg 2016.

than in younger controls (12.5\%). Clavijo-Alvarez et $\mathrm{al}^{14}$ also reported an association between brain injuries and age. In their study, the brain injury rate in patients younger than 45 years was only $0.4 \%$ compared with $11.7 \%$ in those 65 to 74 years old, $13.7 \%$ in those 75 to 84 years old, and $14.5 \%$ in those older than 85 years. A recently published study from Australia reported a substantial increase in hospitalized traumatic brain injuries in the older population (ie, $\geq 65$ years old) during a 13 -year study period. ${ }^{16}$ In particular, the rate of hemorrhagic-related brain injuries (ie, subdural and subarachnoid hemorrhage) increased considerably, whereas no increase in concussive injuries was observed. The investigators considered that the increased use of anticoagulation and antiplatelet agents probably contributed to the increase in fall-related traumatic brain injuries.

Indeed, Rogers et al $^{9}$ observed that coumadin use was a strong predictor of mortality in the geriatric trauma group. Therefore, they conducted a study to determine whether a novel ED protocol would improve the outcomes of these patients. ${ }^{17}$ The socalled ACT Alert (Anti-Coagulation and Trauma) was implemented to improve the care and outcome of mildly injured geriatric patients at high risk of head bleed. The included patients were older than 65 years and used anticoagulation agents, had a Glasgow Coma Score of at least 13, and had sustained a head trauma within the previous 24 hours. The protocol initiated 3 procedures in the ED: 1) workup by an ED response team within 15 minutes, 2) the international normalized ratio test within 20 minutes, and 3) a head computed tomographic scan within 30 minutes. The ACT Alert population showed improved trends with respect to their outcome compared with the control group. According to these investigators, the risk of serious consequences resulting from delayed traumatic brain injury diagnosis was probably decreased.

According to previously published investigations, spine injuries occur in 1.7 to $16.9 \%$ of adult patients with facial fractures. ${ }^{1,5,13,18,19}$ The highest rate of spine injuries in general (16.9\%) and cervical spine injuries in particular (14.9\%) was reported by Fischer et al. ${ }^{5}$ These extraordinarily high rates are probably explained by the fact that the investigators focused exclusively on high-speed injuries (ie, motor vehicle collisions). Hackl et $\mathrm{al}^{18}$ reported a clearly lower rate of cervical spine injuries (6.7\%), but they also observed an association between trauma energy and cervical spine injuries; traffic accidents were the most common reasons. Importantly, geriatric patients were especially prone to combined facial and spine injuries. Moreover, not only the rate of spine injuries in general but also that of fatal spine injuries has been observed to be higher in patients older than 65 years. ${ }^{20}$ The exclusion of cervical spine injuries in patients with facial trauma in general and geriatric patients with facial trauma in particular is of utmost importance.

In the present study, significant predictors of AI were high-speed trauma mechanisms (ie, MVAs and falls from a height; $P<.001$ ). Conversely, groundlevel falls are often classified as low-energy mechanisms. Nevertheless, ground-level falls were associated with high mortality in geriatric patients, because the fall-related mortality was $4.4 \%$ in the elderly compared with $1.6 \%$ in younger controls. ${ }^{7}$ As reported by Harvey and Close,${ }^{16} 80 \%$ of brain injury hospitalizations in elderly patients were due to falls, and the great majority of falls were on the ground level. In the present study, a notably high rate of AI (26.1\%) was observed in patients who had ground-level falls. Unfortunately, as noted by Rogers et al, ${ }^{9}$ elderly patients with trauma who have fallen are frequently under-triaged. The additional finding that most geriatric patients with facial fractures sustained their injury from ground-level falls $^{21}$ calls for attentiveness from facial surgeons, and ground-level falls in geriatric patients should not be underestimated.

One drawback of the present study is that the mortality rate is probably somewhat underestimated, 
because some patients were referred to other hospitals for follow-up treatment. It also would have been interesting to clarify the reasons for death in more detail, which was too challenging because of the retrospective study design. For the same reason, standardized scoring systems could not be used for trauma patients (such as the Injury Severity Score, Trauma Injury Severity Score, and Abbreviated Injury Score), which would have been beneficial. However, the severity of AI was categorized further as multiple AIs and polytrauma, which the authors consider meaningful enough for the specific purposes of this study.

AIs are substantially more frequent and severe in geriatric patients than in younger adults and the elderly die considerably more often of their injuries. The results emphasize that elderly patients require specific attention and multi-professional collaboration in the diagnosis and sequencing of trauma treatment.

\section{References}

1. Thorén H, Snäll J, Salo J, et al: Occurrence and types of associated injuries in patients with fractures of the facial bones. J Oral Maxillofac Surg 68:805, 2010

2. Béogo R, Dakouré P, Savadogo LB, et al: Associated injuries in patients with facial fractures: A review of 604 patients. Pan Afr Med J 16:119, 2013

3. Scherbaum Eidt JM, De Conto F, De Bostoli MM, et al: Associated injuries in patients with maxillofacial trauma at the Hospital São Vicente de Paulo, Passo Fundo, Brazil. J Oral Maxillofac Res 4:1, 2013

4. Follmar KE, Debruijn M, Baccarani A, et al: Concomitant injuries in patients with panfacial fractures. J Trauma 63:831, 2007

5. Fischer K, Zhang F, Angel M: Injuries associated with mandible fractures sustained in motor vehicle collisions. Plast Reconstr Surg 108:328, 2001
6. Keller JM, Sciadini MF, Sinclari E, et al: Geriatric trauma: Demographics, injuries, and mortality. J Orthop Trauma 26:161, 2012

7. Spaniolas K, Cheng JD, Gestring ML, et al: Ground level falls are associated with significant mortality in elderly patients. J Trauma 69:821, 2010

8. Rau SC, Lin TS, Wu SC, et al: Geriatric hospitalizations in fall-related injuries. Scand J Trauma Resusc Emerg Med 22:63, 2014

9. Rogers A, Rogers F, Bradburn E, et al: Old and undertriaged: A lethal combination. Am Surg 78:711, 2012

10. Tillou A, Kelley-Quon L, Burruss S, et al: Long-term postinjury functional recovery. JAMA 149:83, 2014

11. Min L, Cryer H, Chan CL, et al: Quality of care delivered before vs after a quality-improvement intervention for acute geriatric trauma. J Am Coll Surg 220:820, 2015

12. Mangram AJ, Mitchell CD, Scifflette VK, et al: Geriatric trauma service: A one-year experience. J Trauma 72:119, 2012

13. Kloss FR, Tuli T, Häckl O, et al: The impact of ageing on craniomaxillofacial trauma-A comparative investigation. Int J Oral Maxillofac Surg 36:1158, 2007

14. Clavijo-Alvarez JA, Dleyiannis FW, Peitzman AB, et al: Risk factors for death in elderly patients with facial fractures secondary to falls. J Craniofac Surg 23:494, 2012

15. Brasilero BF, Passeri LA: Epidemiological analysis of maxillofacial fractures in Brazil: A 5-year prospective study. Oral Surg Oral Med Oral Pathol Oral Radiol Endod 102:28, 2006

16. Harvey LA, Close JCT: Traumatic spine injuries in older adults: Characteristics, causes and consequences. Injury 43:1821, 2012

17. Rittenhouse K, Rogers A, Clark E, et al: The ACT Alert: Preliminary results of a novel protocol to assess geriatric head trauma patients on anticoagulation. Am Surg 81:408, 2015

18. Hackl W, Hausberger K, Sailer R, et al: Prevalence of cervical spine injuries in patients with facial trauma. Oral Surg Oral Med Oral Pathol Oral Radiol Endod 92:370, 2001

19. Mukhejree S, Abninav K, Revington PJ: A review of cervical spine injury associated with maxillofacial trauma at a UK tertiary referral centre. Ann R Coll Surg Eng1 97:66, 2015

20. Majdan M, Brazinova A, Mauritz W: Epidemiology of traumatic spinal cord injuries in Austria 2002-2012. Eur Spine J 25:62, 2016

21. Toivari M, Helenius M, Suominen AL, et al: Etiology of facial fractures in elderly Finns during 2006-2007. Oral Surg Oral Med Oral Pathol Oral Radiol 118:539, 2014 